\title{
The Technologisation of Education and the Pathway to Depersonalisation and Dehumanisation
}

\author{
Ronald Samuel Laura ${ }^{1} \&$ Fraser Douglas Hannam ${ }^{2}$ \\ ${ }^{1}$ Professor in Education, The University of Newcastle, Callaghan, Australia \\ ${ }^{2}$ Professional Experience Unit, The University of Newcastle, Callaghan, Australia; Lecturer, Alphacrucis College \\ at Cardiff \\ Correspondence: Mr Fraser Douglas Hannam, Professional Experience Unit, The University of Newcastle, \\ Callaghan, Australia.
}

Received: March 21, 2017

Accepted: April 20, 2017

Online Published: May 26, 2017

doi:10.20849/ajsss.v2i2.155

URL: https://doi.org/10.20849/ajsss.v2i2.155

\begin{abstract}
Contrary to the conventional wisdom, it is a central contention of this piece that there exists a growing crisis of depersonalisation and dehumanisation which has emerged from the computechnological texturing of contemporary society. We shall endeavour to show that the primary mode of electronic communication is characterised by the covert depersonalisation of human relations. Depersonalisation, as we shall define this computechnological dimension of the problem refers to the condition of human relationships wherein we have come progressively to substitute face-to-face human exchange in preference for technologically mediated forms of electronic communication. One significant paradox to be explored here will reveal that we personalise and anthropomorphise our computechnology, while simultaneously depersonalising ourselves and treating others as if they were machines. The criterion of 'employment-efficiency-expectation', as we call it, is now determined by the work capabilities of computechnology, not the work-potential of humans defined in terms of integrated well-being and mental health. When we increasingly treat each other as machines, and our machines as humans, the time has truly come to reflect not only on how we value our relationships with each other, but on the way in which we have come, somewhat mindlessly, to value the very tools of technology which depersonalise and in turn dehumanise those relationships.
\end{abstract}

Keywords: computer paradoxes, computer-pedagogy, depersonalisation, dehumanisation, incivility, loneliness and depression

\section{Introduction}

Technology is now a ubiquitous part of how we 'do life' and it is no great feat to take up the lens of historical hindsight and point an accusing finger back through time in order to identify the antecedents surrounding the origins of its various indiscretions against humanity. We do not speculate that there was ever a single historical point where technological and educational stakeholders convened with the sole and deliberate purpose of seeking out the most efficient manner of dehumanizing the next generation, of leaving our children alienated and relationally emaciated through an infusion of technological outcomes into the school curriculum, be it in the name of economic prosperity and / or collective control. Nonetheless, these things are happening.

The burden of this piece is to show that this mindless obsession with computechnology has led our culture to become blind to the almost imperceptible impacts on human relationships and the forms of depersonalisation which have resulted from it. To keep this paper within manageable bounds we focus here on one outcome of what we refer to as the 'compuphilia paradox'. In this context, the paradox is meant to reveal the extent to which society has so fervently adopted computechnology that it has now become commonplace to anthropomorphise (i.e.. ascribe human attributes to our computechnological devices, while at the same time unabashedly and progressively treating humans as if they were machines. The implications of this paradigmatic shift have momentous pedagogic and sociocultural consequences. Many people now 'christen' their computer with a name and excuse its aberrant behaviour, while mechanistic breakdowns become anthropomorphised descriptions of otherwise apposite and compassionate concerns for humans. For example, when a computer is slow in booting up, or exhibiting aberrations of mechanical functionality, it is not unusual for users to say that the computer is 'exhausted," 'suffering from Monday morning blues', 'temperamental', 'depressed', has a virus, or is even 'on 
strike", all of which are descriptions traditionally reserved for and ascribed to humans. On the other hand when a person works less effectively at a workplace task, or misunderstands a supervisory request, it is not unusual for the person involved to be reprimanded and contemptuously castigated with phrases such as, 'come on, get with the program', 'get plugged in', 'boot up', or even, 'get connected'. Indeed, we now live in a culture which expresses adulation for an especially diligent worker with a compliment such as, 'he works like a machine'. We even use mechanistically inspired metaphoric phrases of accolade such as 'you are a machine' to simulate a mechanistic attributes of personal identity to a human being. In essence, we sympathetically treat the mechanistic failings of our computers as human shortcomings, but dispassionately chastise those who display human shortcomings by directly suggesting that they need to be more machine-like. Moreover, when the performance outcomes of humans are admirable, many people bedazzled by computechnology have no hesitation in passionately praising them by describing them as 'muscle-machines', though they are in fact 'humans.'

Given this paradoxical situation, the onus on curriculum developers and educators now becomes one of recanting the indiscretions of the computechnological dimensions of depersonalisation and dehumanisation that have become embedded features of the computechnological pedagogy of paradigmatic World View. The goal is to strike a balance between the introduction of technological 'tools', while at the same time ensuring that these instruments are not implemented at the expense of the highly personalised interactions and modalities of deep connectivity between student and teacher.

\section{A Society of Technological Giants without Vision}

Given the increasing awareness of the pedagogic importance of the depth of bonding between students and teachers, there is a mordant irony in the fact that so little critical reflection exists which questions whether computer-based learning is systematically depersonalising the school environment. To understand the source of this facet of the paradox we first need to comprehend why western culture is far too quick to applaud the success of technology, while at the same time, reluctantly slow to recant its indiscretions. Because technology is now a defining characteristic of the modern age, so to say, we are as a culture more inclined to embrace new technologies unreflectively than to assess them critically. One plausible explanation for this discrepancy is that technology has itself come to function as the standard measure of progress and thus as the primary means of resolving our problems, whether they be technological or not. Another explanation concerns the fact that technology, by its very nature, is introduced not after it has been evaluated, but so it can be evaluated. Feedback comes from the testing ground of the human societal guinea pig. Longitudinal research into far deeper problematic issues on the anthropological side of the coin have been a long time coming and in most cases are too late to placate the uptake and spread of the digital 'infection'. And as so often happens when we realise we can do something, we tend to neglect even that simple check '...but should we do it? The naive presumption is that surely nothing negative can flow from such a pure intension and the almost divine-like providence that technology so generously bestows on us.

This being so, it is perhaps unsurprising that computechnology has been assimilated into the school curriculum more as matter of course, than as a consequence of critically rational assessment and philosophical discussion. Within the culture of what we have called compuphilia, the trust we put in computer-based education may not so much have been earned, as it has been inherited as part of our socio-cultural commitment to, and ethos of a technological worldview. Is it not possible that we have become so bedazzled by the power of technology to let us walk upon the earth as giants that we have failed in the educational context to discern that we now walk the earth as blind technological giants who have lost our way? The transition was almost seamless and rather than be satisfied with its position as a discretionary instrument within our pedagogical tool kit, the god of technology has usurped the position of pedagogy itself. Stoll states, "a poor substitute it is this virtual reality where frustration is legion and where- in the holy name of Education and progress-important aspects of human interaction are relentlessly devalued" (Stoll, 1995, p. 4).

Technological power does not in itself bequeath philosophical vision, but without that vision we have only a shadow of a picture of what it is that gives education its value and in turn confirms that the educational goals we seek are actually worth pursuing. In a study conducted by Warschauer et al. (2004) on computer use in American schools, for example, he concluded that placing computers and internet connections, especially in low-SES schools in and of itself "does little to address the serious educational challenges faced by these schools" (Warschauer et al, 2004, p. 585). Thus, even when it is so admirably discerned that the bonds between students and teachers represent an integral constituent of effective pedagogy, the suspicion that computer -based education could possibly serve as an impediment to such bonding rarely occurs. Surely if technology were so appealing we should not try to compete for the engagement of our students? Surely somewhere embedded in the code is something far more engrossing than anything a trained, experience and professional school teacher might 
hope to employ as a means to connect with the hearts of their students? Certainly it is easier to assume the former rather than face the possibility that our lessons might not be as appealing as we first thought and so hand them over to the machine rather than fight for a deep emotional connection with our classes?

\section{Secularising the Sacred}

The concept of technology is admittedly multifaceted, and it is no part of our purpose here to get mired in the semantic morass of definitional demarcation which surrounds it. Suffice to say, there exists a subtle but monumental difference between the sense of technology as it refers to the specific machines, tools or devices we use to direct or facilitate our interactions within the world around us, on the one hand, and the sense of technology as a 'World View', on the other. The point of important distinction we are endeavouring to bring to bold relief here is that we no longer simply use technology; we imbibe it, and we actually live it. This being so, technology is ascribed an authority and priority in our lives that we believe is tantamount to theologizing it. We literally experience our existence in the midst of our technologies, and we use technology to become co-creators of a technological world. Our lives, our movements, and even our values become technologically textured. In a bizarre sense it could be said that in so doing, we unwittingly 'sacralize' what is in essence 'secular' and we secularize what is in essence sacred. Part of the problem is that we have, as a culture, been seduced into believing that technology, in general, is the panacea or 'cure-all' for all our problems. This being so, we theologize it by idealising it as a form of salvation. It is touted not only as a form of socio-salvation, but is regarded in some cases as a modality of spiritual salvation, by way of which wholeness, peace and self-completion can be brought to fruition.

Because we are surrounded by and immersed in the technological texturing of our lives, we tend not to notice how profoundly technology has impacted on every aspect of the way we live, including the sacredness, as it were, of our relationships with each other.

Indeed, what might be called the 'theology of technology' has become so pervasive that educators are seduced into thinking that they cannot live without the materialist catechism it extols. This being so, we are blinded to the growing body of evidence and human experience which strongly suggests that we cannot live without it, when the truth is that Computechnology has become so ubiquitous that it is now increasingly difficult to live with it.

\section{The Myth of Computopia}

We are now in a position to make explicit our main reservations about computer- based education. The persistent claims and promises for the most recent innovations in computer mediated communication are inescapable. This technological 'advance', it is argued, will bring to our lives knowledge, power, pleasure, personal liberation, and unlimited shopping (Brook \& Boal, 1995, viii). On this rational, whatever is lacking in our lives can be provided by way of greater access to new forms of communication, entertainment and information, all of which can be provided by the computer. Indeed, we can now confess our sins online at the Vatican, order pizza to our door and play chess with someone on the other side of the world. We have manufactured the vacuous life of nothing, and surrendered it to the ether. The 'net' has indeed captured us in its 'web'.

Nonetheless, let us make plain that we have no wish to deny the many benefits which computechnology makes available both inside and outside the classroom. Lest we be misunderstood, we are not proposing that students surrender their computechnological tools at the school gates before entering our halls. It is clear that they are presently so adept in wielding their tools that they would feel lost without them. Nor do we wish to contest that in certain contexts computechnology may both encourage and facilitate the cultivation of personal relationships across the continuum of human interchange. Using computechnological devices such as Zoom, FaceTime, Skype and WeChat to communicate with distant loved ones, or for business negotiations, etc, especially on the other side of the world, represents a frontier breakthrough on the part of IT science.

The problem to which we are alluding is a different one, and its resolution depends primarily on qualitative considerations, not on quantitative ones. The first consideration to be addressed relates to the fact that while it is to be admitted that appropriate contexts exist for the use of computechnology, we have as a culture, partly as a consequence of vested political and economic interests, generalized the specific cases of its acceptable use in such a way that the application of any specific form of technology in question becomes universal. For example, it has been only a few years since it was acknowledged that enrolment procedures for students who resided long distances from the university could be facilitated, and thus their enrolment procedures made more administratively 'efficient' by enrolling 'on-line'. Shortly thereafter, however, it was legislated that enrolments for all students would have to be organized on-line. From a specifically justified principle for the use of computechnology in one context, an almost imperceptible extrapolation was made which universalised the principle in other contexts in which it has not been justified. This being so, we thereby diminish options for 
students by standardising procedures which by their very nature discourage face to face interchange. Because provision of on-line courses for distance students may be justified, it clearly does not follow, by parity of reasoning, that any justification has been provided to show that all university courses should be offered on-line and only on-line, though it is incontestable that such degree courses as this already exist.

By embracing the theologized form of secular life within which the technology of electronic communication is embedded, we at one and the same time marginalize and compromise the value of face to face interchange. The more that the use of computers is demanded of us, the more we shall be distracted from the salient value of cultivating truly deep face to face human experiences. From this value presumption, however, it does not follow that people should never spend time at a computer screen. Nor does it mean that if you spend time at a computer, you will never have any deep human experiences. It just means that the burgeoning obsession with computechnology creates its own subculture within which its constituents are covertly encouraged to rely ever more fervently on the machine s\&n puts pressure on people to live human lives" (Lakoff, 1995, p. 124). This being so, our reliance upon computechnology and its various modes of communication (eg. Mobile phones, video games, tablets and internet transactions, etc) become ever more embedded, taken for granted, and thus socially ubiquitous, without philosophical reflection as to why this should be so.

Should we not be asking whether our resolute commitment to computer-based learning serves unwittingly to devalue the qualitative experience of our children's education by increasingly substituting face to face classroom interchanges with mechanically mediated informational transmissions characterised primarily by the processing of data? Is it not worth considering that the more time we encourage school children to spend in the isolated context of the computer screen, the less time they spend actually interacting with their teachers, and the less time they spend learning how to interact with others to form bonds of trust and loyalty, not grounded in electronically mediated messaging. Should we not be concerned philosophically that the pedagogic goal of computopia may in the end serve inadvertently to propagate contexts of depersonalization, not only in schools, but in both the workplace and the wider community? (Laura \& Chapman, 2009)

It is not surprising that many of the 'value-based' qualities such as resilience, perseverance, consistency, confidence, relational intelligence, leadership skills, and service to the community are the very virtues that experienced and proficient teachers seek to inculcate in their students (Becker and Luther 2002). It has also been established that endeavouring to teach such values with electronically based devices serves to compromise the pedagogic efficacy of student capacity for value appropriation (Duckworth and Yeager 2015; Seider 2012), It has also been argued that computechnologically structured teaching is not as conducive to developing social and moral sensibilities and may even prove to impede the holistic progress of the child, particularly in the areas of creativity and socio-emotional health. For example, Gardner and Davis (2013); Turkle (2011); Uhls et al. (2014) found that preteens who refrained from using their devices for five days (in favor of face-to-face interactions) were more adept at reading and interpreting human emotions.

\section{Computechnolical Colonisation}

That computechnology has facilitated and proliferated the forms of communication now available to us in incontestable. It is salutary to remind ourselves, however, that the more forms of mechanistic communication we increasingly institutionalise and embed educationally to expand the culture of computechnology, the increasingly less intimate and more depersonalised scenarios become. Indeed, electronically mediated methods eventually become a substitute for the face to face human interactions and learning transactions that the electronic medium was ironically designed to promulgate. Simply put, the argument advanced here affirms that the depersonalisation of human relationships and the modalities of dehumanisation which follow from it are an ineluctable consequence of universalising the highly mechanised modes of communication which characterise computechnology. This is a salient reason why the mind set which results from the now growing global obsession with computechnological interaction can be regarded as a veritable addiction. We have called this addiction 'compuphilia' which presently features as a socially legitimated and educationally enshrined syndrome which unreflectively encourages the love of computechnology, without adequately understanding the extent to which this pedagogic commitment defies validation. Moreover, the burgeoning universality and ubiquity of computechnological colonisation is by its very nature an egregious threat to the cultivation and preservation of empathetically inspired and loving relationships. The failure to understand the nature of this threat is why the comutechnological paradigm has devoured its competitors and created a constantly expanding empire of vested interest and economic supremacy. In consequence, we have mindlessly and cavalierly anthropomorphised our machines, while at the same time dehumanising ourselves in the service of their preservation and imperialism. Consequently, these contrary dispositions give rise to serious moral antinomies which have been badly neglected. As intimated earlier, humans are now expected by their employers- or we demand it of ourselves- to 
work at our computers, not only throughout the day, but sometimes tirelessly in to the night. One promise of computopia was to give us all, even school children, more leisure time, but the truth is that when we have more leisure time, we all too often spend it working or 'playing' at the computer in virtual isolation. I-Pods, I-Pads, and Tablets are just another symptom of this growing trend towards what we shall call 'technological isolationism'. It is well worth noting that to date insufficient attention has been paid to the deleterious physical and mental effects of these new forms of social isolation, with regard to loneliness, alienation, depression, and increasing rates of suicide(See, for example, Laura, R.S. et al, The New Social Disease, 2010). It is no longer uncommon to see a group of young people who have decided to get together for dinner sitting in isolation, huddled up with their phones individually texting, emailing, shopping, playing games, etc. In such circumstances they are together, but paradoxically, they are not together. This truth is witnessed by the fact that they only rarely feel obliged to disengage from their phones to talk to each other. They may have agreed to come out to be together, but in reality, their union is an idle ritual of voluntary solitude and loneliness. While they have gathered together, they are disconnected by having voluntarily chosen the purgatory of 'self-isolation'. They are 'linked in' but it is by proxy -a faceless interface acting as a 'go-between'. More often than not they are on Faceless 'Facebook', interacting with hundreds of 'friends' they do not really know -and are essentially desensitized to this reality.

Because we spend progressively more time communicating through, or working in isolation with our computechnological devices, we tend not to notice that we are spending less time, and certainly less quality time with each other. In particular, given the technologically structured contexts of learning through computechnology, the potential for creating deep and bonding relationships between teachers and students has become decidedly diminished. Potentially intimate and vital personal relationships are in essence being channeled without much, if any notice on society's part, into impersonal one- dimensional, and mechanistically mediated ones. We have slipped, that is to say, almost imperceptibly into a different state of consciousness, or simulacrum of human relationship, which structurally encourages the substitution of face to face forms of human interchange with technologically mediated forms of communication, even when face-to-face communication is available.

Applauditory claims that computer networks improve student collaborations are far less convincing than has been presumed. A scholarly literature has now accumulated to show that the notion of group assignments benefit students most when everyone is together simultaneously in the one room. Of particular significance here is research from Harvard Psychiatrist, Edward Hallowell whose concept of the human moment provides a powerful argument for the paramount importance of teacher -student personalisation. Hallowell, for instance, writes of the loss of an interactive phenomenon which he calls the human moment, that is, an authentic psychological experience that can only be generated by individuals occupying the same physical space (1999, p. 59).

Hallowell's argument is that human moments have become increasingly rare within modern society and that its absence from our lives holds the potential to lead to alienation and social disconnection. For Hallowell, human moments are defined in terms of energy exchange amongst humans. What the human moment requires, for example, is for us to make provision to set aside some of the things with which we are mechanically occupied and to disengage ourselves from our computechnological contraptions, and to reconnect with the person or persons who are present with us. When this is achieved, states Hallowell, a personal and powerful context of energy interchange is created which is itself an integral part of intimate communication. It is in this way that human moments are said to "quickly create a force field of exceptional power" $(1999$, p. 60), the positive effects of which can be felt long after the moment has been experienced, thereby providing a balance between personalised and highly humanised interchanges on the one hand, and depersonalised and dehumanised interactions with our machines on the other.

Hallowell states that when engaged in human moments, "[people begin to think in new and creative ways; mental activity is stimulated" (1999, p. 60). Extrapolate Hallowell's concept of the human moment to the reality of students 'facing-off' with their computers instead of their teachers and the problem of depersonalization is brought into sharp focus. Hallowell's extensive research in this area strongly establishes the positive outcomes of those forms of interchange which arise out of a context of a creatively energized moments of human connectivity that far outweigh the depersonalized benefits of any collaboration of disembodied thoughts sent across a network. Moreover, if one considers that university students live and study in proximity to each other, at least during semester, the question arises why such computer networking is required to facilitate group work. If the goal of teaching a concept such as cooperation is to be maximized, it is essential for students to work together in the same room at the same time, at least some of the time. By virtue of their group interaction students can quickly come to recognize emergent problems or dynamics of group conflicts and resolve them accordingly. 
(Griffiths, T. \& Cooper, S., 2005) The situation we have at the moment is pernicious, as student environments in schools and especially in tertiary institutions are structurally designed to have students work in virtual isolation with their computechnological devises.

Given the foregoing reflections, it is clear that the educational commitment of western culture to technologisation has resulted in the depersonalization of some of the most fundamental and salient aspects of human interchange. This being so, far more thought needs to be given to understanding the extent to which the technologically based educational shift to computer- based learning has compromised the integrity of our educational experience. Not only have technological applications hastened the shift of educational purpose, but they have resulted in a reduction in face-to-face human contact and a reduction in the contexts for human interchange and interaction within the educational milieu. (McDevitt, T. M., \& Ormrod, J.E., 2004). There is little doubt that such technologically based forms of education are rooted both in our social separations and in our alienation from nature. In turn they encourage not only depersonalized ways of thinking but also depersonalized modes of being and living in isolation which are then disseminated into the wider community. When all is said, the substitution of technological innovation for the phenomenon of human interchange represents a deep wound to the human spirit.

The more time we dedicate educationally to our technological conveniences: the more time, for example, that individuals spend at a computer, and the less time they or we could be spending building personal relationships which in turn make us more rather than less alive and more rather than less like the inert machines with which we surround ourselves. If too much of our educational time is taken up learning an extrinsic forms of skills based training designed to ready students for their place in the workforce, we may in fact be doing far too little to prepare the children of the world for life. There comes a point where the economically rationalised pursuit of more technological learning will actually bring us less wisdom and less understanding.

For those amongst us who are in the field of education, or are ourselves educated within the framework of high-tech environments (an ever increasing majority), there is an urgent necessity to redress the balance of the high-tech educative experience with high-contact educative environments. The type of learning experience proffered here involves more than the provision of skills in readiness for work. It involves a form of intimate connectivity, connectivity with other human beings, and connectivity with the living things of this planet. Education must reaffirm its commitment to preserve the educative contexts of face-to-face human interchange which serve to humanize rather than dehumanize us.

Reassuringly, Semenova et al. (2016), have found that the basic definition of scholastic 'interaction' has emerged relatively unscathed from the technological grinder -that it remains a process of mutual influence: "The pedagogical process is a bilateral interaction: the teacher on the one side and the student on the other side." (p. 2564). This discussion is augmented by Hood \& Lander (2016), in their comparison between preformatted lecture presentations disseminated through university portals and 'live lectures'. They found that the -

“......pedagogic discourse the students encounter in the live lectures is one in which, relatively speaking, knowledge is more often exchanged in the here-and-now of the material situational setting, more often involves movements between more congruent and metaphoric construals of meaning, and is more often negotiated in the 'me-and-you' of the speaker / addressee interaction" (p. 38).

Similarly, Grasedieck, (2016) in an aptly name study 'Not computers, only teachers can make education exciting', identified that "only person-to-person learning can ensure the competencies of the next generation" (p.14). It would seem that there is something fundamental to being a human being and the personalised process of knowledge transfer and more importantly 'meaning' creation that grows organically out of the 'to and fro' of live pedagogic interaction. Arguably facts, and perhaps even knowledge, can flow through technological conduits but meaning and wisdom, it would appear, are teased, goaded and knitted between two needles of teacher and student face-to-face interaction.

The god of technology is certainly a cold, impersonal and relentless teacher of children. It provides immediate feedback each and every time in an infinitely patient robotic loop. But it won't teach patience or delayed gratification. Its loop will ensure a level of mastery not possible in the world, but it will not impart intrinsic motivation, perseverance and the gumption to see a task through to completion. Radesky et al. (2016 ) re-empowers not only educationalists, but parents and caregivers:

.... clinicians can remind parents that they are their child's best teacher, and the best application cannot parallel the developmental benefits of hands-on, structured, face-to-face, or outdoors play. When children do learn new things from applications or educational programming, parents should help their child apply this new knowledge to the 3-dimensional world around them by exploring the new concept through play or 
conversation .... For example, if parents show a child how to use a tablet's camera to take photos and create stories, the child will likely see tablets as a creative tool, rather than only serving entertainment or soothing purposes. (p. 507).

\section{Conclusion}

We have from the outset made it clear that our primary objective in this piece has been to explore the sociocultural phenomenon of what we have identified as 'compuphilia'. Despite the many benefits of computechnological development, we have been slow as a culture of technophiles to recant its indiscretions and reflect critically upon the impact which compuphelia is having, particularly among schoolchildren worldwide, in the pursuit of loneliness through the loss of genuine intimacy of deep rather than cosmetic or sexually utilitarian relationships of convenience. We have in essence witnessed the birth of a global culture which secularises many of the things that were once sacred, while simultaneously 'sacrilising' many of the things that were once secular. In so doing, we are turning the world of human relationships on its head. Admittedly, we have only had time to tease out some of the neglected implications of compuphelia, as they pertain to the depersonalisation of human relationships and the dehumanisation of human beings as a consequence. It is incontestable that we live in the era of technological giants, but we have endeavoured to bring into bold relief the deeper truth that without serious philosophical reflection, we will inevitably become a global culture of ' blinded giants' who have lost our way and our sense of purposive direction. Leadership in education should be designed to emancipate us from myopic conceptual schemes and the commercial infrastructures which imprison us. We need to restore the place of value in our pedagogies and put in perspective the preoccupation with testing. Making people good at testing is not the same as making them into good or happy people, or in making them good at life, which is not necessarily the same as making them good at their jobs. Far too many people give up having a good life in exchange for having a good job. What if we discovered that having a good life involved transforming the value orientation of yourself and the world around you? What if we focused education more on helping students to make the world a better place? What if we taught them the value of enhancing their compassionate empathy for each other, rather than using each other as a means to an end, be it for sexual pleasure, self aggrandisement or the disempowerment of others?

Most of us know that computechnology can empower us and make us very strong, but we need to know also that compuphilia can make us very weak, because obsession is a form of addiction, and addiction is a form of paralysis of imagination, leading to conformity. Conformity leads to promulgating the Status Quo, and we do not make the world a better place by keeping the world as it is. We tend to forget, for example, or prefer not to be reminded that the status of computechnology depends in large part on the corporate vested interests of the companies that produce computer technology which is designed to be obsolete and out of date at the time of its being launched. This being so, the newness of its marketing introduction will soon be superseded by new technologies, ironically already existing and waiting in line to usher in the next wave of sales that sustain the commercial goal of relentless marketability.

Lest we be misunderstood, it has been no part of our purpose to deny that computer technology can serve to facilitate communication with others who are remote from us, or in proximity, depending upon circumstances, and whether the medium of contact is undertaken by way of e-mail, videoconferencing, teleconferencing, on-line banking, home shopping, electronic voting or telecommuting.

Notwithstanding these benefits, we have been concerned to argue here that the potential for integrated well-being and the forming of deep and trusting relationships not only between teachers and students, but between us all is an integral factor in educational outcomes. (Monfries, M \& McAlpine, R., 2005).

Our view is that the value of all this is being jeopardised by the increasing reliance on computechnology as the predominant medium within which education is administered and mediated at virtually every level of teaching. A central concern of this piece has been to show that such electronic technologies can easily become depersonalising and dehumanising, when the computehnological relationships they galvanise are regularly substituted for the face to face personal modes of human contact and interchange, which by their very nature have the potential to be intrinsically richer than electronically mediated ones. This is as true in the educational context as it is in society generally. When we sacralise technology, we are at one and the same time marginalising the potential of our humanity, and in the final analysis it is the promulgation of our humanity and the empathy for service to others in need that gives us the best chance of a better world.

Put another way, the argument advanced here has endeavoured to establish that notwithstanding its many benefits, the much applauded technologisation of the modern world is leading ineluctably to the depersonalisation of fundamentally intimate aspects of human relations. Not only have we come to mediate our 
natural experiences of human relationships via mechanistic interactions, but we have technologized our lives in such a way that it is becoming ever more difficult to conduct the vast array of our communications with each other in any other way. This is the lamentable legacy of compuphilia which now confronts us.

We have argued that while computechnology may have a salient role to play in education, compuphilia serves inadvertently to weaken the unions of loyalty, commitment and trust between teachers and students which would otherwise enhance educational achievement and levels of student satisfaction. The bonds of loyalty and trust, deriving from genuinely intimate relationships, feature as essential elements in the dynamics of all human relationships, but they are absolutely critical to loving and truly creative ones (Zins, J.E., Weissberg, R.P., Wang, M. C., Walberg, H.J., 2004).

We have endeavoured to show that while technology has made electronic modes of communication increasingly accessible to us, the forms of communication upon which we have come progressively to depend are themselves for the most part, decreasingly intimate. This being so, we have been concerned to argue that the ensuing loss of intimacy alters the nature of education irrevocably, and not necessarily for the best.

Having surrounded ourselves with machines, and having now brought the computer into our homes and schools, technology has itself become a value which is being used as a measure of the worth of the world around us. When all is said, the substitution of technological innovation for the phenomenon of human interchange represents a deep wound to the human spirit. We thus become caught in the web of a bizarre moral ambiguity. We still claim we value people, but we are not entirely certain what we value them for. Within the context of this moral ambiguity, it is difficult to see how the relationship of bonding between students and teachers, so critical to educational outcomes, can be maximally fostered.

\section{Future Work}

Future research is necessary in order to assess the longitudinal impact of compuphilia on the holistic development of school children, and in turn upon their capacity to develop themselves into productive and relationally intelligent members of society. Exploration will be needed to ascertain which aspects of technology serve in particular ways that uniquely strengthen the learning experiences of children beyond traditional methods. Once this point is established, it will be easier to determine the identity and importance of those exclusive learning domains and purposes upon which strategies for both the deployment, and confinement of technological tools can be identified. Research should also aim to isolate and expose those areas of learning for which computechnological depersonalisation and dehumanisation are clearly deleterious to the learning process and long term wellbeing of the students

\section{References}

Becker, B., \& Luther, S. S. (2002). Social-emotional factors affecting achievement outcomes among disadvanataged students: Closing the achievement gap. Educational Psychologist, 37(4), 197-214.

Brook, J., \& Boal, I. (1995). Resisting the Virtual Life: The Culture of Politics and Information. San Francisco: City Light.

Duckworth, A. L., \& Yeager, D. S. (2015). Measurement matters: Assessing personal qualities other than cognitive ability for educational purposes. Educational Researcher, 44(4), 237-251. https://doi.org/10.3102/0013189X15584327

Gardner, H., \& Davis, K. (2013). The app generation: How today's youth navigate identity, intimacy, and imagination in a digital world. New Haven, CT: Yale University Press.

Grasedieck, D. (2016). Not computers, only teachers can make education exciting. Proceedings of MAC-ETeL 2016, 7.

Griffiths, T., \& Cooper, S. (2005, March). Social and emotional wellbeing in schools: A review of systems' policies. Education Connect, (1).

Hallowell, E. (1999). The Human Moment at Work. Harvard University Press.

Hood, S., \& Lander, J. (2016). Technologies, modes and pedagogic potential in live versus online lectures. International Journal of Language Studies, 10(3), 23-42.

Lakoff, G. (1995). Body, Brain and Communication. In Brook Boal (Ed.), Resisting the Virtual Life: The Culture of Politics and Information. San Francisco: City Light.

Laura, R., \& Chapman, A. (2009). The Paradigm Shifting Health.

Laura, R., \& Marchant, T. (2002). Surviving the High Tech Depersonalisation Crisis: Don't Let Technology Steal 
Your Soul. Queensland: Goldbold publishing.

Laura, R., Marchant, T., \& Smith, S. (2010). The New Social Disease. The University Press of America, London, New York.

McDevitt, T. M., \& Ormrod, J. E. (2004). Child Development: Educating and Working With Children and Adolescents: Second Edition. New Jersey: Pearson Education International.

Monfries, M., \& McAlpine, R. (2005). The impact of attachment in an educational setting. Education Connect, 2, 3-8.

Radesky, J. S., Eisenberg, S., Kistin, C. J., Gross, J., Block, G., Zuckerman, B., \& Silverstein, M. (2016). Overstimulated Consumers or Next-Generation Learners? Parent Tensions about Child Mobile Technology Use. Annals of Family Medicine, 14(6), 503-508. https://doi.org/10.1370/afm.1976

Seider, S. (2012). Character compass: How powerful school culture can point students toward success. Cambridge, MA: Harvard University Press.

Semenova, L. A., Kazantseva, A. I., Sergeyeva, V. V., Raklova, Y. M., \& Baiseitova, Z. B. (2016). Pedagogical Interaction in Hugh School, the Structural and Functional Model of Pedagogical Interaction. International Journal of Environmental \& Science Education, 11(9), 2553-2566. https://doi.org/10.12973/ijese.2016.706a

Stoll. (1995). Silicon Snake Oil. New York: Doubleday.

Turkle, S. (2011). Alone together: Why we expect more from technology and less from each other. New York: Basic Books.

Uhls, Y., Michikyan, M., Morris, J., Garcia, D., Small, G., Zgourou, E., \& Greenfield, P. (2014). Five days at outdoor education camp without screen improves preteen skills with nonverbal emotion cues. Computers in Human Behavior, 39, 387-392. https://doi.org/10.1016/j.chb.2014.05.036

Warschuuer, M., Knobel, M., \& Stone, L. (2004). Technology and Equity in Schooling: Deconstructing the Digital Divide. Educational Policy, 18, 562-587.

Zins, J. E., Weissberg, R.P., Wang, M. C., \& Walberg, H.J. (Eds.) (2004) Building academic success on social and emotional learning: What does the research say. New York: Teachers College Press.

\section{Copyrights}

Copyright for this article is retained by the author(s), with first publication rights granted to the journal.

This is an open-access article distributed under the terms and conditions of the Creative Commons Attribution license (http://creativecommons.org/licenses/by/4.0/). 